\title{
Non-ARV Prescriptions and Medication Burden among Commercially Insured U.S. HIV Patients
}

\author{
Koram $\mathrm{N}^{* 1}$, Vannappagari $\mathrm{V}^{1,2}$, Sampson $\mathrm{TJ}^{1}$ and Panozzo $\mathrm{CA}^{3}$ \\ ${ }^{1}$ GlaxoSmithKline, Research Triangle Park, NC, US \\ ${ }^{2}$ Gillings School of Global Public Health, University of North Carolina-Chapel Hill, NC, US \\ ${ }^{3}$ Department of Population Medicine, Harvard Medical School and Harvard Pilgrim Health Care Institute, Boston, \\ Massachusetts, US
}

*Corresponding author: Koram N, MPH, PhD, WorldWide Epidemiology, GlaxoSmithKline, 5 Moore Drive, Mail Stop: 5.4300.4B, Research Triangle Park, NC 27709-3398, USA, E-mail: nana.e.koram@gsk.com

Citation: Koram N, Vannappagari V, Sampson TJ, Panozzo CA (2014) Non-ARV Prescriptions and Medication Burden among Commercially-Insured U.S. HIV Patients. J Pharm Drug Devel 2(4): 403. doi: $10.15744 / 2348-9782.1 .603$

Received Date: October 01, 2014 Accepted Date: December 19, 2014 Published Date: December 23, 2014

\begin{abstract}
Accelerated aging and higher co-morbidity prevalence have increased non-antiretroviral (ARV) medications for HIV patients. We examined, over a 12 month period, non-ARV medication burden among HIV-positive patients 18-49 and $\geq 50$ years using a comprehensive U.S. healthcare claims database in an age-and-gender matched analysis (1:3 matching ratio of cases to controls). Primary outcomes of interest included the median and mean number of unique non-ARV drug substances during the one month period with the highest number of prescriptions filled for each individual, and the mean number of unique classes of medication. We identified 9,510 HIV-positive patients aged $\geq 50$ years and 28,530 controls; 15,737 HIV-positive patients aged 18-49 years and 47,211 controls. Sixty percent of HIV-positive patients aged $18-49$ years had $\geq 1$ co-morbidities versus $40 \%$ of controls; $82 \%$ of HIV-positive patients aged $\geq 50$ years had $\geq 1$ co-morbidities versus $66 \%$ of controls. Among patients aged 18 - 49 years, cases were prescribed $5.3( \pm 4.2)$ classes of drugs over 12 months; controls were prescribed $4.2( \pm 3.4)(\mathrm{p}<0.0001)$. Cases were prescribed a median of 4 [interquartile range (IQR): 2-7] unique drugs, controls 3 (IQR: 2-6). Thirty-two percent of cases were prescribed $>5$ drugs versus $19 \%$ of controls. Among patients aged $\geq 50$ years, cases were prescribed $7.2( \pm 5.3)$ drug classes versus controls $[5.6( \pm 4.4) ; \mathrm{p}<0.0001]$. Cases were prescribed a median of 6 (IQR: $3-10$ ) drugs, controls 4 (IQR: $2-8$ ). Fifty percent of cases were prescribed $>5$ medications versus $32 \%$ of controls. Overall, HIVpositive patients were more likely to have $\geq 1$ co-morbidities and be prescribed significantly higher numbers of non-ARV unique drugs and drug classes compared to HIV-negative controls.
\end{abstract}

\section{Introduction}

Since the availability of combination antiretroviral therapy in 1996 in the developed world, HIV infection has gradually become more of a chronic condition, allowing patients to live longer, and resulting in an aging population [1,2]. In the US, approximately $75 \%$ of the HIV-positive population is at least 40 years old, and older individuals continue to be diagnosed with HIV [2]. Due to aging, the prevalence of various co-morbid conditions, including cardiovascular disease, hypertension and diabetes, has increased, and causes of death have gradually shifted from opportunistic infections such as Pneumocystis jiroveci pneumonia (PCP) to endstage liver and kidney disease and non-HIV-related malignancies [1,2]. Beyond standard aging effects, there is also an accelerated aging effect associated with HIV-infection, causing HIV-infected individuals to experience age-related conditions at a younger age compared to the general population $[3,4]$. Some research suggests that this issue may be particularly common in patients with below normal CD4+ T-cell counts (normal defined as at least 500 cells/ml), although it has also been observed in patients with normal or above normal CD4+ T-cell counts [5].

In HIV management, it has been established that high pill burden and treatment regimen complexity can contribute to adherence problems and lead to poor health outcomes [6,7]. In an analysis of a U.S. health insurance database, it was reported that HIV patients on an antiretroviral therapy (ART) regimen of a single pill a day were more likely to be adherent and less likely to be hospitalized compared with those patients on three or more pills a day [8]. Fixed dose combination drug therapies, while being cost-effective [9], have also helped reduce the number of HIV medications taken daily by HIV-positive patients, thus improving adherence [8]. However, the aging of the HIV-positive population and the increasing prevalence of co-morbidities have resulted in higher non-antiretroviral (ARV) medication burden for this population, as evidenced by several studies. Data from a case-control study in Italy, for instance, indicate that HIV-infected patients, compared to the general population, have a significantly higher risk of acquiring non-infectious co-morbidities, particularly at younger ages [10]. HIV-infected patients were also more likely to have at least two or more co-morbidities [10], implying that HIV-infected patients are thus more prone to be on other medication apart from ARVs. A Canadian study reported that $83 \%$ of its HIV-positive participants were taking both ARVs and non-ARVs, and that 
ARV s comprised of less than $50 \%$ of the total pill burden for these patients [11]. As well, a study conducted among Swiss HIV patients found that $68 \%$ of them took at least one co-medication, and among those taking co-medications, $37 \%$ took three or more. Polypharmacy has been found to be more frequent in older patients and in females [12]. In another study, 134 HIV patients were taking over 1,500 active medications (mean: 11.5 medications per patient), and only $30 \%$ of them were ARVs or for HIV-related opportunistic infections [13].

The primary goal of this analysis was to characterize and compare the distribution of selected non-ARV prescriptions and all non-ARV medication burden among HIV-positive and negative patients 50 years and older, as well as among HIV-positive and negative patients aged 18-49 years over a 12 month period. For each of the four patient sub-groups, the specific objectives included the following: (1) describing the distribution of select demographic and clinical factors; (2) determining the top 25 non-ARV prescription drugs most frequently used over a period of 12 months; (3) determining the top 25 classes of drugs most frequently used, and the proportion of each population using select classes of drugs; (4) estimating and comparing the means and medians of the total number of unique non-ARV drug substances (both generic and branded), and the total number of unique classes of medication during the observation period among patients 50 years and older, as well as among patients 18-49 years; and (5) estimating the proportion of patients from each subgroup taking multiple prescription non-ARV unique drug substances over the observation period. Additionally, we also examine the relationship between non-ARV medication burden and co-morbidities among HIV-infected patients.

\section{Materials and Methods}

The Clinformatics ${ }^{\mathrm{Tm}}$ DataMart Multiplan (IMPACT) database, a product of OptumInsight Life Sciences, Inc., and a comprehensive, de-identified U.S. healthcare claims database consisting of over 116 million unique patient records, was analyzed. Approximately $76 \%$ of all patients in the database have both medical and pharmacy benefits and, on average, 31 months of enrollment/claims information; the annual attrition rate is roughly $15-25 \%$. The data are collected from at least 46 different healthcare plans serving members across nine census regions. Clinformatics ${ }^{\mathrm{Tm}}$ DataMart Multiplan (IMPACT), a product of OptumInsight Life Sciences, Inc. (aka IHCIS) is a certified HIPAA compliant resource that is consistent with 45 C.F.R. $\$ 164.514$ (b) (1). These are de-indentified data and hence do not require IRB approval or patient consent.

All outpatients with full pharmacy benefits, a diagnosis of HIV [International Classification of Diseases, $9^{\text {th }}$ Revision, Clinical Modification (ICD-9-CM) codes 042 (AIDS) or V08 (asymptomatic HIV)] in their medical history, and who were continuously enrolled for at least 12 months were included in the analysis. Outpatients with an enrollment gap of greater than one day were excluded from the analysis. Additionally, HIV-positive patients had to have been diagnosed prior to the start of the observation period (that is, prior to April 1, 2012). All HIV-positive patients who met this criterion were included in the analysis. Non-ARV medications and classes of drugs were identified using the National Drug Codes (NDC). The study utilized a matched design, focusing on exact matching for gender and frequency matching for age without replacement in a ratio of 1:3 (cases: controls). All patients aged 80 years and older were assigned an age of 80 years. Over a 12-month observational period (April 1, 2012 to March 31, 2013), data for HIV-positive patients 50 years and older were compared to that for age-and-gender matched HIV-negative patients, while data for HIV-positive patients 18-49 years were compared to that for age-and-gender matched HIV-negative patients. A 1:3 matching ratio of cases to controls was selected for increased statistical power.

For the selection of HIV cases, the following criteria were used: all cases had to be first diagnosed with HIV prior to April 1, 2012. All cases had to have continuous eligibility (with pharmacy benefits) between April 1, 2012-March 31, 2013. Breaks in eligibility of less than one month were considered continuous. All cases also had to be at least 18 years of age as at April 1, 2012. For the selection of HIV controls, the following criteria were used: all controls had to be free from a diagnosis of HIV over all time. All controls had to have continuous eligibility (with pharmacy benefits) between April 1, 2012-March 31, 2013. Breaks in eligibility of less than one month were considered continuous. All controls had to be at least 18 years of age as at April 1, 2012.

For each patient subgroup, baseline and demographic characteristics were tabulated. These included the following covariates: gender and age (matching factors); presence of co-morbidity/co-infection; any ARV use; availability of laboratory values; CD4+ T-cell count/ml (for HIV-positive patients only); and viral load/ml (for HIV-positive patients only). Cut-off points for CD4+ T-cell counts were selected according to the World Health Organization (WHO) criteria for stages of HIV disease, which defines severe HIV-associated immunodeficiency as CD4+ T-counts <200/ml; advanced HIV-associated immunodeficiency as CD4+ T-cell counts 200-<350/ml; mild HIV-associated immunodeficiency as CD4+ T-cell counts 350-<500/ml; and no significant HIVassociated immunodeficiency as CD4+ T-cell counts $>500 / \mathrm{ml}$ [14]. Cut-off points for viral load/ml were selected based on prior published work in HIV [15]. The distributions of the top 10 non-ARV prescription drugs and classes of drugs most frequently used were obtained, as well as the frequency of distribution for select classes of drugs. For drug class, the Universal System of Classification (USC) level 4 was used. The primary outcomes of interest were the median and mean number of unique non-ARV drug substances (both generic and branded) during the one month period with the highest number of prescriptions filled for each individual, and the mean number of unique classes of medication. To compare the mean medication burden among patient subgroups (that is, comparison between HIV positive and negative patients 50 years and older, and then comparison between HIV positive and negative patients aged 18 to 49 years), the distributions of the various populations were first determined. Based on the non-normal distributions obtained, the Wilcoxon-Mann-Whitney test was used to estimate p-values to determine if the means were significantly different among the various patient subgroups. 


\section{Results}

A total of 9,510 HIV positive patients aged 50 years and older met the inclusion criteria, and were matched to $28,530 \mathrm{HIV}$ negative patients 50 years and older. Additionally, a total of 15,737 HIV positive patients aged 18-49 years were identified, and were matched to 47,211 HIV-negative patients aged 18-49 years. Demographic and clinical data for HIV-positive patients 50 years and older were compared to that for HIV-negative patients 50 years and older, while data for HIV-positive patients aged 18-49 years were compared to that for HIV-negative patients aged 18-49 years (Table 1).

\begin{tabular}{|c|c|c|c|c|c|c|c|c|}
\hline \multirow{3}{*}{ Characteristic } & \multicolumn{8}{|c|}{ Patient Subgroup } \\
\hline & \multicolumn{2}{|c|}{$\begin{array}{c}\text { HIV }+>=50 \text { years } \\
(\mathrm{N}=9510)\end{array}$} & \multicolumn{2}{|c|}{$\begin{array}{c}\text { HIV- > }=50 \text { years } \\
(\mathrm{N}=28530)\end{array}$} & \multicolumn{2}{|c|}{$\begin{array}{l}\text { HIV + 18-49 years } \\
(\mathrm{N}=15737)\end{array}$} & \multicolumn{2}{|c|}{$\begin{array}{l}\text { HIV- } 18-49 \text { years } \\
\quad(\mathrm{N}=47211)\end{array}$} \\
\hline & n & $\%$ & n & $\%$ & $\mathbf{n}$ & $\%$ & $\mathbf{n}$ & $\%$ \\
\hline \multicolumn{9}{|l|}{ Gender } \\
\hline Female & 2,048 & 21.54 & 6,144 & 21.54 & 4,803 & 30.52 & 14,409 & 30.52 \\
\hline Male & 7,462 & 78.46 & 22,386 & 78.46 & 10,934 & 69.48 & 32,802 & 69.48 \\
\hline \multicolumn{9}{|l|}{ Age (in 2012) } \\
\hline $18-29$ & - & - & - & - & 2,298 & 14.60 & 6,894 & 14.60 \\
\hline $30-39$ & - & - & - & - & 4,945 & 31.42 & 14,835 & 31.42 \\
\hline $40-49$ & - & - & - & - & 8,494 & 53.97 & 25,482 & 53.97 \\
\hline $50-59$ & 7,107 & 74.73 & 21,321 & 74.73 & - & - & - & - \\
\hline $60-69$ & 2,177 & 22.89 & 6,531 & 22.89 & - & - & - & - \\
\hline $70-79$ & 182 & 1.91 & 546 & 1.91 & - & - & - & - \\
\hline $80+$ & 44 & 0.46 & 132 & 0.46 & - & - & - & - \\
\hline \multicolumn{9}{|l|}{ Presence of co-morbidity/co-infection } \\
\hline No & 1,750 & 18.40 & 9,780 & 34.28 & 6,347 & 40.33 & 28,118 & 59.56 \\
\hline Yes & 7,760 & 81.60 & 18,750 & 65.72 & 9,390 & 59.67 & 19,093 & 40.44 \\
\hline \multicolumn{9}{|l|}{ ARV use } \\
\hline No & 3,068 & 32.26 & 28,519 & 99.96 & 6,883 & 43.74 & 47,191 & 99.96 \\
\hline Yes & 6,442 & 67.74 & 11 & 0.04 & 8,854 & 56.26 & 20 & 0.04 \\
\hline \multicolumn{9}{|l|}{ Lab values available } \\
\hline No & 5,209 & 54.77 & 21,842 & 76.56 & 8,887 & 56.47 & 37,761 & 79.98 \\
\hline Yes & 4,301 & 45.23 & 6,688 & 23.44 & 6,850 & 43.53 & 9,450 & 20.02 \\
\hline \multicolumn{9}{|l|}{ CD4+ T-cell counts/ml } \\
\hline No recording during period & 9,422 & 99.07 & 28,530 & 100.00 & 15,566 & 98.91 & 47,211 & 100.00 \\
\hline$>0$ and $<200$ & 9 & 0.09 & - & - & 7 & 0.04 & - & - \\
\hline $200-<350$ & 9 & 0.09 & - & - & 18 & 0.11 & - & - \\
\hline $350-<500$ & 13 & 0.14 & - & - & 45 & 0.29 & - & - \\
\hline$>=500$ & 57 & 0.60 & - & - & 101 & 0.64 & - & - \\
\hline \multicolumn{9}{|l|}{ Viral load/ml } \\
\hline No recording during period & 8,175 & 85.96 & 28,530 & 100.00 & 13,753 & 87.39 & 47,211 & 100.00 \\
\hline$>0$ and $<500 / \mathrm{ml}$ & 1,216 & 12.79 & - & - & 1,717 & 10.91 & - & - \\
\hline $500-<10,000 / \mathrm{ml}$ & 89 & 0.94 & - & - & 218 & 1.39 & - & - \\
\hline $10,000-<30,000 / \mathrm{ml}$ & 10 & 0.11 & - & - & 19 & 0.12 & - & - \\
\hline$>=30,000 / \mathrm{ml}$ & 20 & 0.21 & - & - & 30 & 0.19 & - & - \\
\hline
\end{tabular}

Table 1: Demographic and clinical characteristics of HIV patients and matched controls

Among HIV-positive patients 50 years and older, 82\% had at least one co-morbid condition, compared with $66 \%$ of controls. Among HIV-positive patients aged 18 to 49 years, 60\% had at least one co-morbid condition compared with $40 \%$ of HIV-negative younger patients who had at least one co-morbid condition (Figure 1). Among the four groups, HIV-negative patients aged 18 to 49 years had the lowest proportions of co-morbidities/co-infections. 


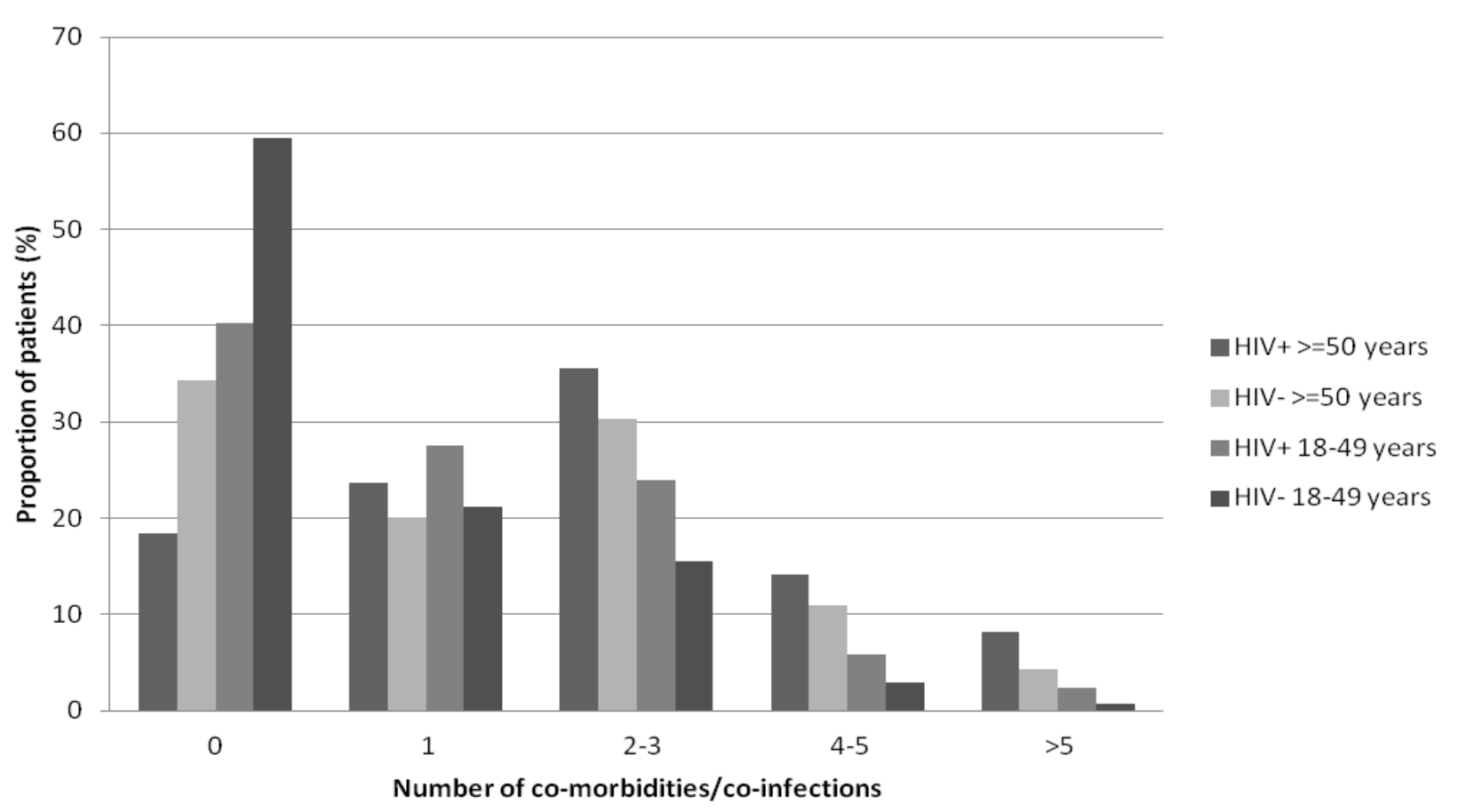

Figure 1: Distribution of co-morbidities/ co-infections among HIV patients and matched controls

Over the 12-month observation period, the most commonly used unique non-ARV prescription drugs among the four patient subgroups were: acetaminophen among HIV patients 50 years and older, and oxycodone among controls; azithromycin among HIV patients 18 to 49 years, and acetaminophen among controls (Table 2). The 3-hydroxy-3-methylglutaryl-coenzyme (HMG$\mathrm{CoA}$ ) reductase inhibitors (32\%) were the most frequently prescribed non-ARV drug class among both HIV patients 50 years and older (32\%) and matched controls (27\%); among both HIV patients 18-49 years and controls, codeine and combination, noninjectable (codeine \& comb, non-inj) was the most frequently prescribed non-ARV drug class (22\% and $17 \%$, respectively) (Table $3)$.

\begin{tabular}{|c|c|c|c|c|c|c|c|c|c|c|c|}
\hline \multicolumn{12}{|c|}{ Patient subgroup } \\
\hline \multicolumn{3}{|c|}{ HIV $+>=50$ years $(\mathrm{N}=9510)$} & \multicolumn{3}{|c|}{ HIV- $>=50$ years $(\mathrm{N}=28530)$} & \multicolumn{3}{|c|}{ HIV + 18-49 years $(N=15737)$} & \multicolumn{3}{|c|}{ HIV- $18-49$ years $(\mathrm{N}=47211)$} \\
\hline $\begin{array}{c}\text { Substance of } \\
\text { non-ARV } \\
\text { prescription drug }\end{array}$ & $\mathbf{n}$ & $\%$ & $\begin{array}{c}\text { Substance of } \\
\text { non-ARV } \\
\text { prescription drug }\end{array}$ & $\mathbf{n}$ & $\%$ & $\begin{array}{c}\text { Substance of } \\
\text { non-ARV } \\
\text { prescription drug }\end{array}$ & $\mathbf{n}$ & $\%$ & $\begin{array}{c}\text { Substance of } \\
\text { non-ARV } \\
\text { prescription drug }\end{array}$ & $\mathbf{n}$ & $\%$ \\
\hline Acetaminophen & 2,049 & 21.55 & Acetaminophen & 4,620 & 16.19 & Azithromycin & 3,294 & 20.93 & Acetaminophen & 6,536 & 13.84 \\
\hline Azithromycin & 1,745 & 18.35 & Azithromycin & 3,580 & 12.55 & Acetaminophen & 2,936 & 18.66 & Azithromycin & 6,289 & 13.32 \\
\hline Lisinopril & 1,321 & 13.89 & Lisinopril & 3,417 & 11.98 & Amoxicillin & 1,824 & 11.59 & Amoxicillin & 4,627 & 9.80 \\
\hline Atorvastatin & 1,247 & 13.11 & Amoxicillin & 3,011 & 10.55 & Valacyclovir & 1,462 & 9.29 & Fluticasone & 3,678 & 7.79 \\
\hline Amoxicillin & 1,173 & 12.33 & Simvastatin & 2,942 & 10.31 & Ibuprofen & 1,425 & 9.06 & Prednisone & 2,671 & 5.66 \\
\hline Zolpidem & 1,081 & 11.37 & Atorvastatin & 2,662 & 9.33 & Fluticasone & 1,374 & 8.73 & Ibuprofen & 2,625 & 5.56 \\
\hline Testosterone & 1,067 & 11.22 & Fluticasone & 2,602 & 9.12 & Ciprofloxacin & 1,305 & 8.29 & Albuterol & 2,500 & 5.30 \\
\hline Ciprofloxacin & 954 & 10.03 & Amlodipine & 2,229 & 7.81 & Doxycycline & 1,240 & 7.88 & Ciprofloxacin & 2,350 & 4.98 \\
\hline Fluticasone & 903 & 9.50 & Prednisone & 1,968 & 6.90 & Zolpidem & 1,207 & 7.67 & Lisinopril & 2,299 & 4.87 \\
\hline Valacyclovir & 903 & 9.50 & Metoprolol & 1,953 & 6.85 & Albuterol & 1,179 & 7.49 & $\begin{array}{l}\text { Methylpredniso- } \\
\text { lone }\end{array}$ & 2,049 & 4.34 \\
\hline
\end{tabular}

Table 2: Top 10 unique non-ARV prescription drugs most frequently used over 12-month period among HIV-positive and negative patients

Among the older patient subgroups, higher proportions of HIV-positive patients, as compared to matched HIV-negative controls, used statins ( $32 \%$ vs. $27 \%$ ), pain medication ( $27 \%$ vs. $21 \%$ ), anti-diabetes medications (11\% vs. $10 \%)$, selective serotonin reuptake inhibitors (SSRIs) (12\% vs. $8 \%$ ), and phosphodiesterase type 4 (PDE4) inhibitors (10\% vs. 6\%) (Figure 2). The use of antihypertensives and anti-hepatitis $\mathrm{C}$ drugs was uncommon in both groups of older patients. Among the younger patient subgroups, higher propotions of HIV-positive patients, as compared to matched controls, used statins (10\% vs. $8 \%$ ), pain medication (22\% vs. $17 \%$ ), SSRIs ( $10 \%$ vs. $7 \%$ ), and PDE4 inhibitors (5\% vs. $2 \%$ ). Approximately $4 \%$ of both HIV-positive and HIV-negative patients aged 18-49 years had used anti-diabetes medications. Additionally, the use of anti-hypertensives and anti-hepatitis C medications was uncommon in both subgroups. 


\begin{tabular}{|c|c|c|c|c|c|c|c|c|c|c|c|}
\hline \multicolumn{12}{|c|}{ Patient subgroup } \\
\hline \multicolumn{3}{|c|}{ HIV $+>=50$ years $(\mathrm{N}=9510)$} & \multicolumn{3}{|c|}{ HIV- $>=50$ years $(\mathrm{N}=28530)$} & \multicolumn{3}{|c|}{ HIV+ $18-49$ years $(\mathrm{N}=15737)$} & \multicolumn{3}{|c|}{ HIV- $18-49$ years $(\mathrm{N}=47211)$} \\
\hline Drug Class & $\mathbf{n}$ & $\%$ & Drug Class & $\mathbf{n}$ & $\%$ & Drug Class & $\mathbf{n}$ & $\%$ & Drug Class & $\mathbf{n}$ & $\%$ \\
\hline $\begin{array}{l}\text { HMG-CoA reduc- } \\
\text { tase inhibitors }\end{array}$ & 3,087 & 32.46 & $\begin{array}{l}\text { HMG-CoA reduc- } \\
\text { tase inhibitors }\end{array}$ & 7,804 & 27.35 & $\begin{array}{l}\text { Codeine \& comb, } \\
\text { non-inj }\end{array}$ & 3,470 & 22.05 & $\begin{array}{l}\text { Codeine \& comb, } \\
\text { non-inj }\end{array}$ & 8,032 & 17.01 \\
\hline $\begin{array}{l}\text { Codeine \& comb, } \\
\text { non-inj }\end{array}$ & 2,510 & 26.39 & $\begin{array}{l}\text { Codeine \& comb, } \\
\text { non-inj }\end{array}$ & 5,784 & 20.27 & $\begin{array}{c}\text { Extended spectrum } \\
\text { macrolide }\end{array}$ & 3,408 & 21.66 & $\begin{array}{c}\text { Extended spectrum } \\
\text { macrolide }\end{array}$ & 6,630 & 14.04 \\
\hline $\begin{array}{l}\text { Extended spectrum } \\
\text { macrolide }\end{array}$ & 1,822 & 19.16 & $\begin{array}{l}\text { Antiarthritics, } \\
\text { plain }\end{array}$ & 3,913 & 13.72 & $\begin{array}{l}\text { Antiarthritics, } \\
\text { plain }\end{array}$ & 2,449 & 15.56 & $\begin{array}{l}\text { Antiarthritics, } \\
\text { plain }\end{array}$ & 5,704 & 12.08 \\
\hline $\begin{array}{l}\text { Antiarthritics, } \\
\text { plain }\end{array}$ & 1,639 & 17.23 & $\begin{array}{l}\text { Extended spectrum } \\
\text { macrolide }\end{array}$ & 3,802 & 13.33 & $\begin{array}{l}\text { Quinolones, } \\
\text { systemic }\end{array}$ & 2,038 & 12.95 & $\begin{array}{l}\text { Hormones, cor- } \\
\text { ticosteriod plain, } \\
\text { oral }\end{array}$ & 4,601 & 9.75 \\
\hline $\begin{array}{l}\text { ACE inhibitors, } \\
\text { alone }\end{array}$ & 1,546 & 16.26 & ACE inhibitors, & 3,748 & 13.14 & Benzodiazepines & 1,663 & 10.57 & $\begin{array}{l}\text { Steriod, inhaled } \\
\text { nasal }\end{array}$ & 3,850 & 8.15 \\
\hline $\begin{array}{l}\text { Quinolones, } \\
\text { systemic }\end{array}$ & 1,546 & 16.26 & Beta blockers & 3,249 & 11.39 & SSRI & 1,593 & 10.12 & $\begin{array}{l}\text { HMG-CoA reduc- } \\
\text { tase inhibitors }\end{array}$ & 3,686 & 7.81 \\
\hline Benzodiazepines & 1,484 & 15.60 & $\begin{array}{l}\text { Hormones, cor- } \\
\text { ticosteriod plain, } \\
\text { oral }\end{array}$ & 3,248 & 11.38 & $\begin{array}{l}\text { Hormones, cor- } \\
\text { ticosteriod plain, } \\
\text { oral }\end{array}$ & 1,592 & 10.12 & Aminopencillins & 3,647 & 7.72 \\
\hline $\begin{array}{c}\text { Non-barbiturates, } \\
\text { other }\end{array}$ & 1,372 & 14.43 & $\begin{array}{l}\text { Proton pump } \\
\text { inhibitors }\end{array}$ & 3,137 & 11.00 & $\begin{array}{l}\text { HMG-CoA reduc- } \\
\text { tase inhibitors }\end{array}$ & 1,572 & 9.99 & SSRI & 3,480 & 7.37 \\
\hline $\begin{array}{l}\text { Proton pump } \\
\text { inhibitors }\end{array}$ & 1,335 & 14.04 & $\begin{array}{l}\text { Quinolones, } \\
\text { systemic }\end{array}$ & 2,782 & 9.75 & Herpes antivirals & 1,566 & 9.95 & $\begin{array}{l}\text { Quinolones, } \\
\text { systemic }\end{array}$ & 3,319 & 7.03 \\
\hline Beta blockers & 1,195 & 12.57 & $\begin{array}{l}\text { Steriod, inhaled } \\
\text { nasal }\end{array}$ & 2,634 & 9.23 & $\begin{array}{l}\text { Steriod, inhaled } \\
\text { nasal }\end{array}$ & 1,541 & 9.79 & $\begin{array}{l}\text { Mus, relax, non- } \\
\text { surg, w/o ana }\end{array}$ & 2,926 & 6.20 \\
\hline
\end{tabular}

HMG-CoA reductase inhibitors $=3$-hydroxy-3-methyl-glutaryl-CoA reductase inhibitors; Codeine $\&$ comb, non-inj $=$ Codeine and combination, non-injectable; ACE inhibitors $=$ angiotensin-convertingenzyme inhibitors; SSRI = selective serotonin reuptake inhibitor; Mus, relax, non-surg, w/o ana = muscle, relaxant, non-surgical, without anabolics

Table 3: Top 10 classes of non-ARV prescription drugs most frequently used over 12-month period among HIV patients and matched controls

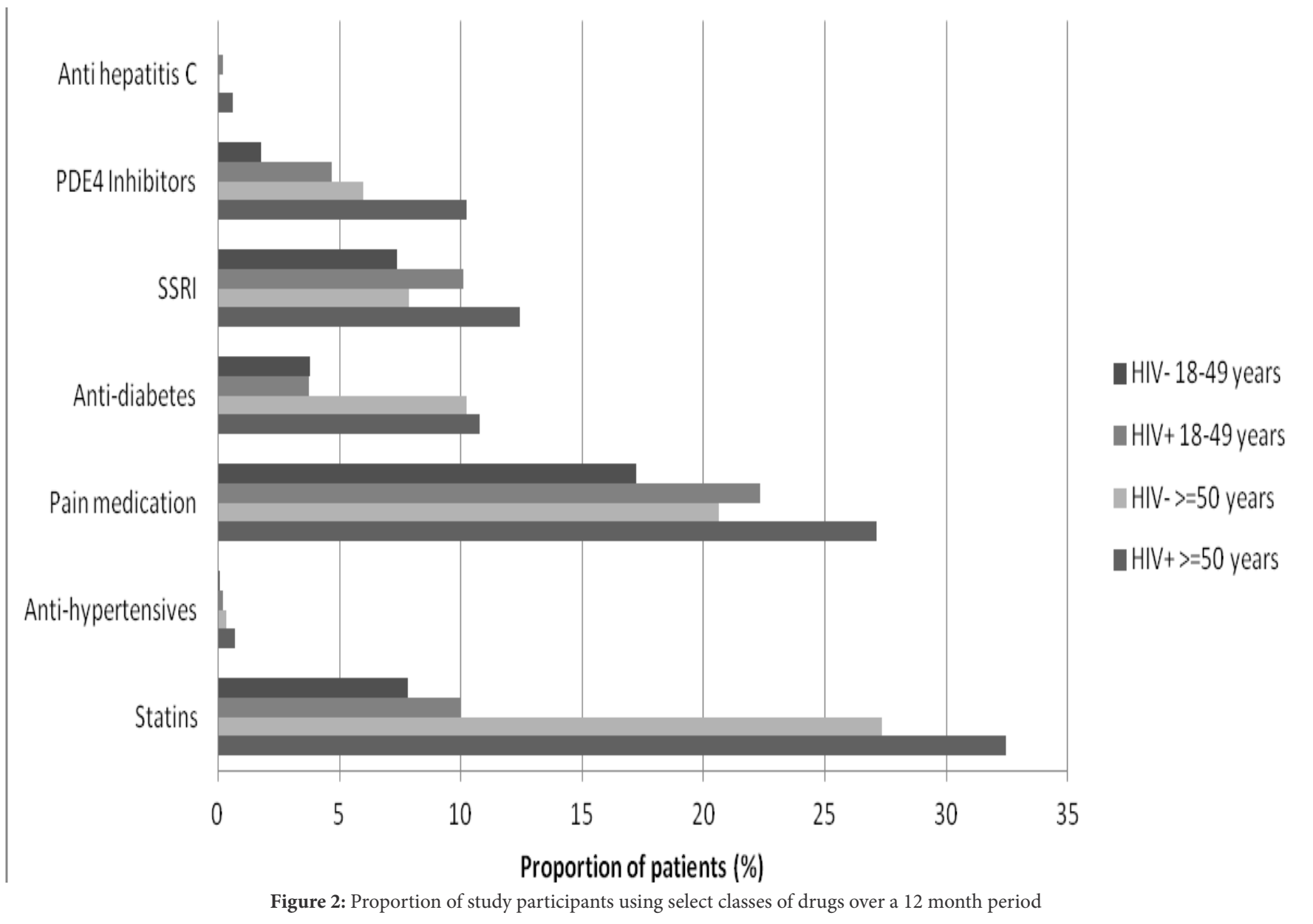


HIV-positive patients 50 years and older were prescribed a mean of $7.2( \pm 5.3)$ classes of drugs over the 12-month period, while controls were prescribed a mean of $5.6( \pm 4.4)$ classes of drugs over the same period $(\mathrm{p}<0.0001)$. The median number of unique drug substances prescribed to HIV-positive patients 50 years and older was 6 [interquartile range (IQR): 3-10], while that for controls was 5 (IQR: 2-8). Close to half of HIV-positive patients 50 years and older were prescribed over 5 non-ARV medications over the 12-month period, as compared with less than a third of controls (Figure 3).

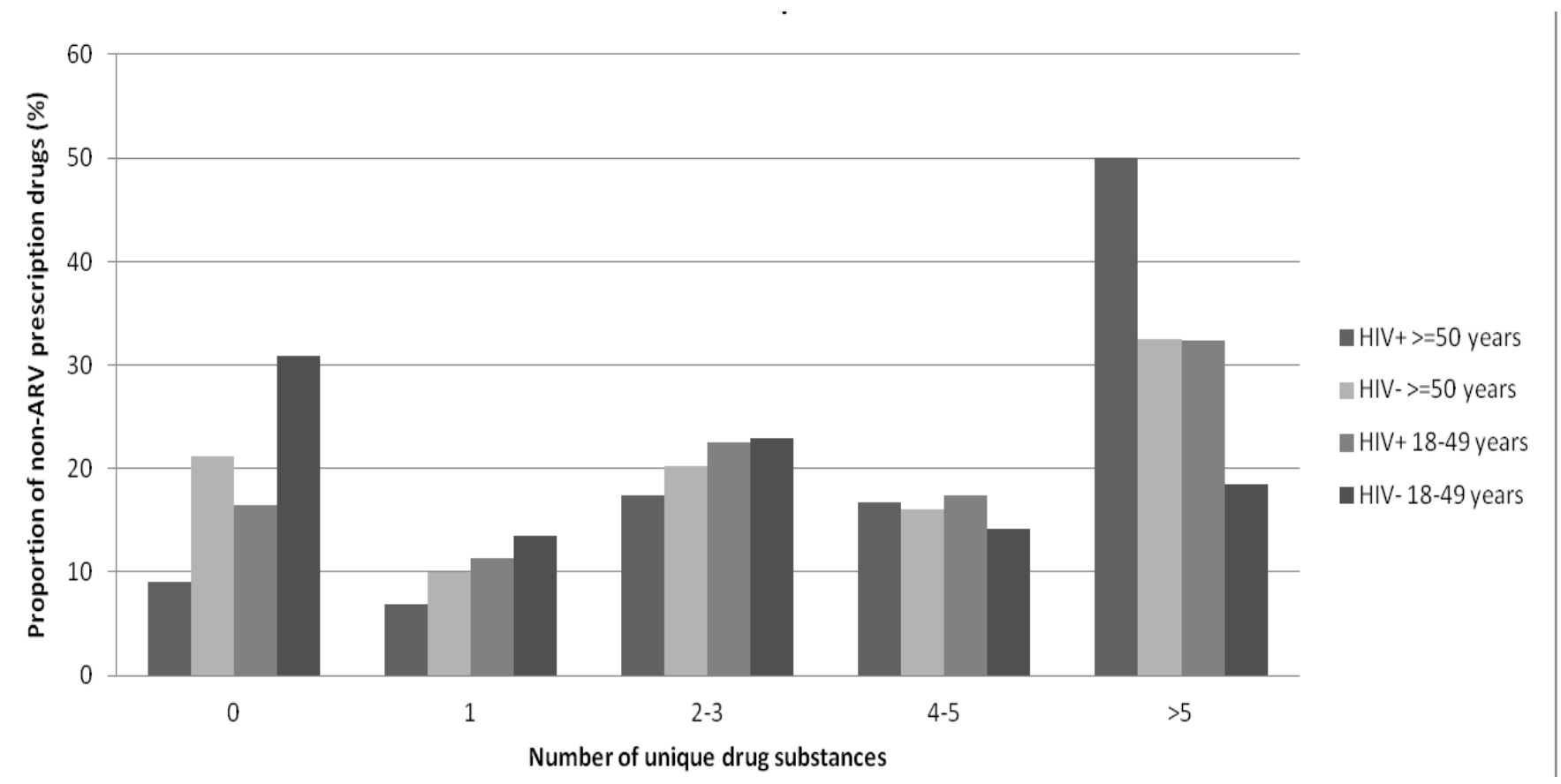

Figure 3: Distribution of non-ARV prescription drugs among patient subgroups over 12 month period

Among the younger patient subgroups, HIV-positive patients were prescribed a mean of $5.3( \pm 4.2)$ classes of drugs over the observation period, while controls were prescribed a mean of $4.2( \pm 3.4)$ classes of drugs over the same time period ( $\mathrm{p}<0.0001)$. HIV-positive patients aged 18-49 years were prescribed a median of 4 (IQR: 2-7) unique drug substances; controls were prescribed 3 (IQR: 2-6) over the same time period. Thirty-two percent of younger HIV-positive patients were prescribed over 5 non-ARV medications over the 12-month observation period, compared with 19\% of controls. Additionally, the proportion of patients in each subgroup with at least one unique drug prescription increased with increasing number of co-morbidities/co-infections reported, and levels off among patients with greater than 3 co-morbid conditions (Figure 4).

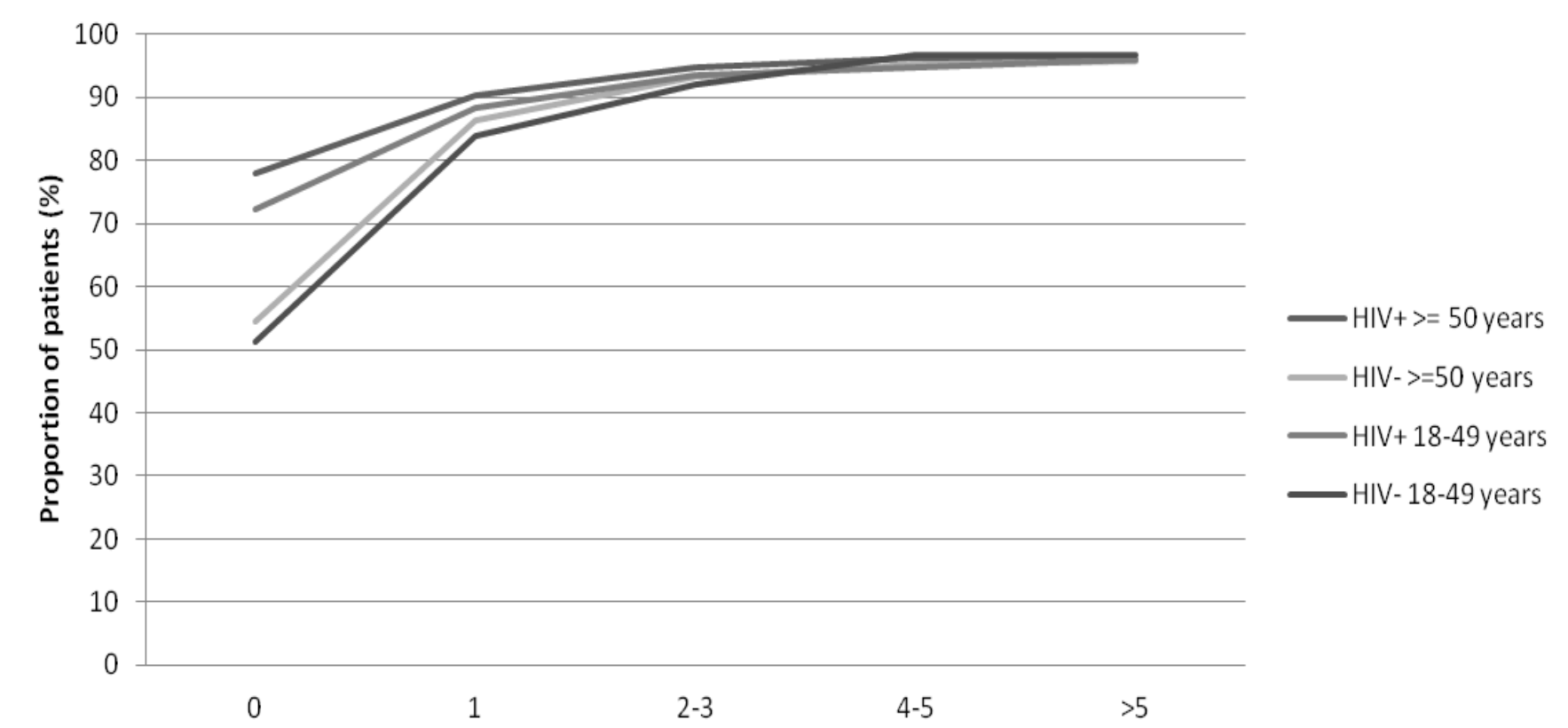

Number of co-morbidities/co-infections

Figure 4: Proportion of with multiple co-morbidities/ co-infections among patients with $\geq 1$ unique drug prescription 


\section{Discussion}

This matched analysis examined the distribution of non-ARV prescriptions and non-ARV medication burden among HIV-positive patients, compared to HIV-negative patients. While much of the literature in this area is focused on HIV-positive patients 50 years and older, this study compares HIV-positive and negative patients aged 18-49 years, as well as those 50 years and older. As well, patients in this study are also age-and-gender matched which allows for a more effective comparison than other unmatched studies. Overall, greater than $80 \%$ of HIV-positive patients 50 years and older, and more than $60 \%$ of HIV-positive patients 18 - 49 years had at least one co-morbid condition, both of which were higher compared with their HIV-negative counterparts. Similarly, in a retrospective analysis of HIV-positive patients 50 years and older reported that greater than $88 \%$ of the study participants had at least one co-morbidity, with hepatitis $\mathrm{C}$ virus co-infection, hypertension and psychiatric disorders being the most frequent co-morbidities found [16]. In a New York City study of HIV-positive patients aged 55 years and older, 89\% had at least one comorbidity, with hypertension, chronic airway disease and diabetes being the three most frequently reported conditions [17]. A third study reported that $92 \%$ of patients at an urban HIV clinic had at least one co-morbidity chart-documented, with hepatitis C, pulmonary disease, high blood pressure and high cholesterol being the most frequently reported conditions [18].

Both groups of HIV-positive patients in this study had more co-morbidities/co-infections as compared with their HIV-negative controls. Study results also indicated a positive linear relationship between the number of reported co-morbidities/co-infections and the proportion of patients with at least one non-ARV drug prescription, although this tapers off among patients with greater than 3 co-morbidities/co-infections. Fewer HIV-negative controls, compared with HIV-positive patients, were prescribed one or more non-ARV medication; of all 4 groups, the group with the lowest proportion of multiple non-ARV prescriptions was HIVnegative patients aged 18-49 years. In published literature, a study of HIV-infected and uninfected veterans found similar results, reporting that not only did HIV-infected patients have a higher risk of liver disease, renal disease and substance use disorder, but they were also at a higher risk of multi-morbidity, also known as polypathology, as compared to their uninfected counterparts [19].

HIV-positive patients 50 years and older were also prescribed a significantly higher number of non-ARV drug classes, and were also more likely to be prescribed over 5 non-ARV medications, compared to HIV-negative patients 50 years and older. Other studies have shown that this is a common occurrence among older HIV-positive patients. For instance, in their study of HIV-positive individuals over 70 years of age in Catalonia, Spain, Mothe et al. (2009) reported high rates of non-ARV-related medication in this patient population, as well as high rates of dyslipidemia, hypertension, diabetes, cardiovascular events, renal function impairment, and suggested that older HIV patients are more likely to benefit from a comprehensive geriatric approach to treatment [20]. A similar pattern of non-ARV medication use was observed among younger HIV-infected patients in our study. Among patients aged 18 to 49 years, HIV-positive patients were also prescribed a significantly higher number of non-ARV medications, as well as a higher number of drug classes compared to HIV-negative patients in the same age group. Younger HIV-positive patients were also more likely to have been prescribed over 5 non-ARV medications over the 12 -month observation period, compared with younger HIV-negative patients.

A review of literature revealed that the mean or median number of non-ARV medications (includes over-the-counter drugs and prescriptions) used by HIV patients in general ranges from 1.1 to 4.2 [17,20-24]. In this study, among HIV patients $18-49$ years, a median number of 4 non-ARV medications were prescribed over the 12-month observation period, while a median of 6 nonARV medications were prescribed for those HIV patients 50 years and older. Since older HIV patients have a higher prevalence of co-morbidities compared with younger patients [12], it was not surprising that a larger number of non-ARV medications were taken by the 50 years and older group. However, these figures are generally higher than those reported in previous work and do not include over-the-counter drugs. Part of the reason for this difference may be due to the fact that we focused on physiciandocumented prescriptions. Some studies rely heavily on self-reported drug use, which could result in underestimations of nonARV medications due to lack of remembrance or embarrassment (recall bias). In this study, but unlike in some previous studies, the mean and median numbers of non-ARV medications were estimated during the one month period with the highest number of prescriptions filled for each patient. This may have also contributed to the higher numbers. Using a privately-insured population may also increase numbers as health care access is less of an issue than in the general population.

Polypharmacy in HIV-positive patients, as described in this study, may result multiple issues, ranging from overall poor drug adherence, to potential drug-drug interactions that may reduce the effectiveness of an HIV regimen [12]. Polypharmacy may also increase the risk of dementia and delirium, as well as increase patients' exposure to potentially harmful medications [25]. In a recent study, polypharmacy was linked to an increased risk of all-cause mortality: in adjusted analysis, the risk of mortality increased by $5 \%$ among those patients on more than five medications [26]. The increase in co-morbidities/co-infections seen in this population is a major contributing factor to polypharmacy.

According to several studies that reported the frequency of various classes of non-ARV prescription drugs, the most commonly prescribed non-ARVs among HIV patients are cardiovascular drugs, including lipid-lowering drugs, statins, drugs of the central nervous system, and anti-hypertensive drugs [12,20]. Similarly in this study, among older HIV patients and controls, HMG-CoA reductase inhibitors were the most commonly prescribed non-ARV drug classes. However in the younger study population, for both cases and controls, the most commonly prescribed non-ARV drug class was codeine \& comb, non-inj. 
There are several limitations associated with this study. Due to the nature of the insurance claims database used, study participants are not necessarily representative of the HIV-infected and uninfected population in the USA. Only those individuals with health insurance are captured. Secondly, we were unable to look at the medication burden of over-the-counter drugs and other alternative non-prescription drugs as this information was also not captured in the database. It is also possible that HIV-negative controls may have yet undiagnosed HIV; however for the 12-month observation period, ICD-9 codes were used to distinguish between patients with a current HIV diagnoses and those without a current HIV diagnoses to ensure that controls were free of an HIV diagnoses over the study period. No adjudication of medication was conducted; however as the primary outcome of interest was the mean medication burden, rather than the medications themselves, this had a limited impact on study results. Additionally, the results of this study are based on a descriptive analysis; however participants were age-and-gender matched to prevent confounding by these variables, as they can influence the presence and type of co-morbidities experienced.

\section{Conclusion}

This study identified a large number of co-morbidities and polypharmacy in HIV-positive patients. In the past, to improve adherence, major efforts were made to reduce HIV medication burden from several pills a day to one daily pill. In comparison, non-ARV prescription medication burden has not been as well studied. This study suggests that non-ARV medication in the HIV population may be high, especially among HIV patients aged 50 years and older, and also among those HIV patients who have multiple co-morbidities/co-infections. A high non-ARV medication burden may suggest that reducing HIV medication burden alone is not enough to improve adherence to HIV medication. Further research is recommended to establish risk factors associated with high non-ARV prescription medication burden and its influence on antiretroviral therapy adherence. This study was unable to evaluate the influence of over-the-counter medication burden due to the nature of the dataset and further research in this area is also recommended.

\section{References}

1. Kirk JB, Goetz MB (2009) Human immunodeficiency virus in an aging population, a complication of success. J Am Geriatr Soc 57: 2129-38. 10.1111/j.15325415.2009.02494.x.

2. Chu C, Selwyn PA (2011) An epidemic in evolution: the need for new models of HIV care in the chronic disease era. J Urban Health 88: 556-66.

3. Slavin S, Elliot J, Fairley C, French M, Hoy J, et al. (2011) HIV and aging: an overview of an emerging issue. Sex Health 8: 449-51.

4. Voskanian A, Merlin J, Selwyn P (2012) HIV/AIDS: Past, present, and future HIV SIG. J Pain and Sympt Manage $43: 359$.

5. Deeks SG, Phillips AN (2009) HIV infection, antiretroviral treatment, ageing, and non-AIDS related morbidity. BMJ 338: a3172.

6. Maggiolo F, Ripamonti D, Suter F (2003) Once-a-day HAART: dream or reality? HIV Clin Trials 4: 193-201.

7. Simone MJ, Appelbaum J (2008) HIV in older adults. Geriatrics 63: 6-12.

8. Sax PE, Meyers JL, Mugavero M, Davis KL (2012) Adherence to antiretroviral treatment and correlation with risk of hospitalization among commercially insured HIV patients in the United States. 10.1371/journal.pone.0031591.

9. Ganguli A, Wang J, Gourley DR (2012) Does combining antiretroviral agents in a single dosage form enhance quality of life of HIV/AIDS patients? A cost-utility study. Res Soc Adm Pharm 8: 157-65.

10. Guaraldi G, Orlando G, Zona S, Menozzi M, Carli F, et al. (2011) Premature age-related comorbidities among HIV-infected persons compared with the general population. Clin Infect Dis 53: 1120-6.

11. Gill M, Cosman I, Ming J, Krentz H (2011) Regimen simplification to reduce daily pill burden, how important is it? 58-9.

12. Marzolini C, Elzi L, Gibbons S, Weber R, Fux C, et al. (2010) Prevalence of comedications and effect of potential drug-drug interactions in the Swiss HIV Cohort Study. Antivir Ther 15: 413-23.

13. Robinson CA, Cocohoba J, MacDougall C, John MD, Guglielmo BJ (2007) Discordance between ambulatory care clinic and community pharmacy medication databases for HIV-positive patients. J Am Pharm Assoc 47: 613-5.

14. World Health Organization (2007) WHO Case Definitions of HIV for Surveillance and Revised Clinical Staging and Immunological Classification of HIVrelated Disease in Adults and Children.

15. Martinson NA, Gupte N, Msandiwa R, Moulton LH, Barnes GL, et al. (2014) CD4 and Viral Load Dynamics in Antiretroviral-Naive HIV-Infected Adults from Soweto, South Africa: A Prospective Cohort. PLoS ONE 9: e96369.

16. Magalhães MG, Greenberg B, Hansen H, Glick M (2007) Comorbidities in older patients with HIV: a retrospective study. J Am Dent Assoc 138 : 1468-75.

17. Shah SS, McGowan JP, Smith C, Blum S, Klein RS (2002) Comorbid conditions, treatment, and health maintenance in older persons with human immunodeficiency virus infection in New York City. Clin Infect Dis 35: 1238-43.

18. Weiss JJ, Osorio G, Ryan E, Marcus SM, Fishbein DA (2010) Prevalence and patient awareness of medical comorbidities in an urban AIDS clinic. AIDS Patient Care STDs 24: 39-48.

19. Goulet JL, Fultz SL, Rimland D, Butt A, Gibert C, et al. (2007) Aging and infectious diseases: do patterns of comorbidity vary by HIV status, age, and HIV severity? Clin Infect Dis 45: 1593-601.

20. Mothe B, Perez I, Domingo P, Podzamczer D, Ribera E, et al. (2009) HIV-1 infection in subjects older than 70: a multicenter cross-sectional assessment in Catalonia, Spain. Curr HIV Res 7: 597-600.

21. Furler MD, Einarson TR, Walmsley S, Millson M, Bendayan R (2003) Use of complementary and alternative medicine by HIV-infected outpatients in Ontario, Canada. AIDS Patient Care STDs 17: 155-68.

22. Furler MD, Einarson TR, Walmsley S, Millson M, Bendayan R (2004) Polypharmacy in HIV: impact of data source and gender on reported drug utilization. AIDS Patient Care STDs 18: 568-86.

23. Wagner S, Gupta S, Waterman F, Zoe-Powers A, Oza D, et al. (2009) Self-reported pill burden as a predictor for adherence in HIV-infected patients. Value Health 12: A116. 
24. Wutoh AK, Brown CM, Dutta AP, Kumoji EK, Clarke-Tasker V, et al. (2005) Treatment perceptions and attitudes of older human immunodeficiency virusinfected adults. Res Soc Adm Pharm 1: 60-76.

25. Edelman EJ, Gordon KS, Glover J, McNicholl IR, Fiellin DA, et al. (2013) The next therapeutic challenge in HIV: Polypharmacy. Drugs Aging $30: 613-28$.

26. Edelman E, Gordon K, Akgun K, Gibert C, Lo Re V, et al. (2013) HIV+ individuals on ART are at risk of polypharmacy: More medication increases mortality. HIV: Treatment, Complications, and Outcomes 250-262.

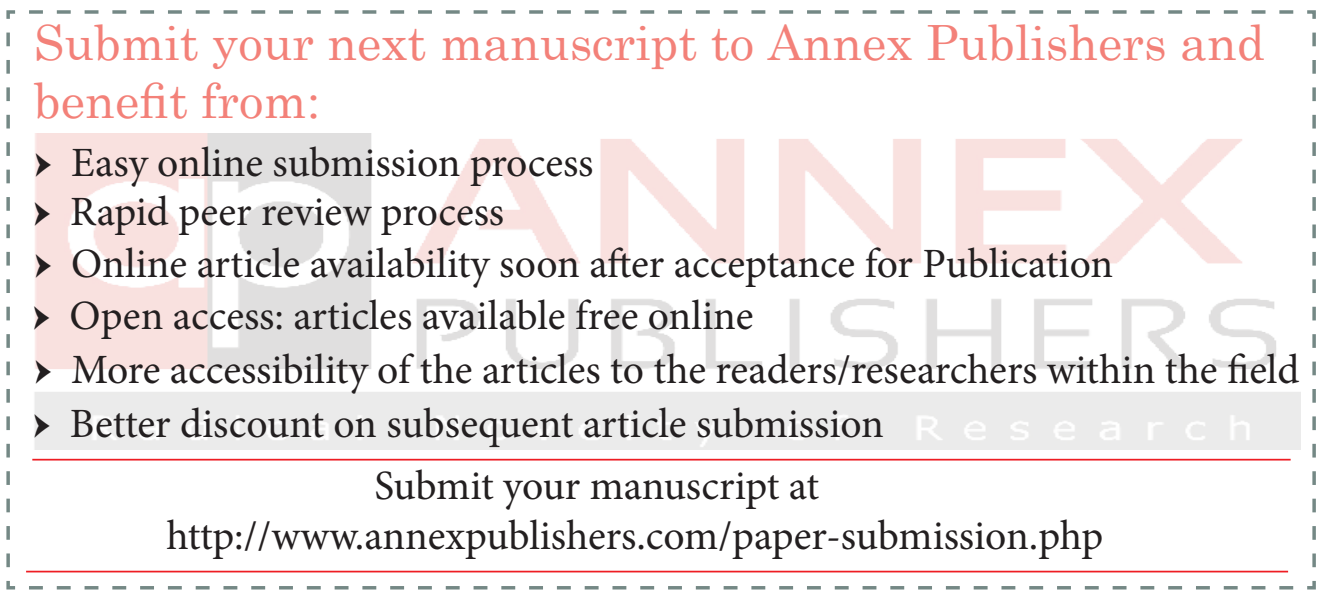

